\title{
Biventricular systolic and diastolic function in a cohort of juvenile-onset systemic lupus erythematosus patients
}

\author{
Mariana Rodrigues ${ }^{1 *}$, Luzia Sampaio ${ }^{1}$, Cláudia Moura ${ }^{2,3}$, Patrícia Costa ${ }^{2,3}$, Iva Brito ${ }^{1,3}$ \\ From 18th Pediatric Rheumatology European Society (PReS) Congress \\ Bruges, Belgium. 14-18 September 2011
}

\section{Background}

Cardiovascular events are the most common single cause of death in systemic lupus erythematosus (SLE). Several studies have described impaired systolic and diastolic function in adults with SLE.

\section{Aim}

The aim of our study was to study left (LV) and right (RV) ventricular function in a population of adolescents with SLE and to discuss their clinical and prognostic implications.

\section{Methods}

Cross-sectional and retrospective study of juvenile-SLE patients' medical records. All patients underwent twodimensional, M-mode, conventional Doppler and tissue Doppler imaging (TDI) to evaluate systolic and diastolic biventricular function.

\section{Results}

13 Juvenile-SLE female patients were included, with disease onset between 6 and 16 years of age (mean 11,8 years), and mean disease duration of 6,6 years (2-15 years). One patient had moderate to severe aortic regurgitation (AoR), one had pulmonary hypertension (HTP), 5 patients had systemic hypertension (HTA); none smoked.

The majority of patients presented at least one criteria of LV diastolic dysfunction. E/A ratio was normal in 6 patients and showed restrictive pattern in 4. E/E` septal ratio showed increased left atrium pressure in 2 patients. $\mathrm{E} / \mathrm{Vp}$ ratio was clearly abnormal in 3 cases, predicting

\footnotetext{
* Correspondence: mariana.j.rodrigues@gmail.com

${ }^{1}$ Pediatric Rheumatology Unit, Hospital São João, Porto, Portugal

Full list of author information is available at the end of the article
}

high mean pulmonary capillary wedge pressure. Reduced propagation velocity of the mitral valve $(\mathrm{Vp})$ was observed in 4 cases, implying impaired relaxation.

LV systolic function was preserved in all cases, with normal Tei index.

RV systolic function was normal in all patients except for one, with AoR (TDI S velocity $9,3 \mathrm{~cm} / \mathrm{s}$, tricuspid annular plane systolic excursion (TAPSE) 14,8 $\mathrm{mm})$.

RV diastolic function markers were altered in some patients: decreased peak velocity of $\mathrm{E}$ wave in 4 patients, with increased A' wave velocity in 1 patient (HTP case). $\mathrm{E} / \mathrm{E}$ 'and $\mathrm{E} / \mathrm{A}$ ratios were normal in all cases. RV outflow tract acceleration time was decreased (implying increased mean pulmonary artery pressure) in the patient with HTP.

Due to the small sample size, no correlations with other clinical or laboratorial markers were statistically significant. BNP was increased only in the AoR patient.

\section{Conclusion}

SLE patients can have subclinical cardiac dysfunction, and diastolic changes can be an early warning sign. Subtle abnormalities of the LV/RV diastolic function were found even in the presence of a preserved systolic function. Preclinical detection of ventricular dysfunction may identify a population at risk requiring early and aggressive interventions for the prevention of cardiovascular events.

\section{Author details}

${ }^{1}$ Pediatric Rheumatology Unit, Hospital São João, Porto, Portugal. ${ }^{2}$ Pediatric Cardiology Department; Hospital São João, Porto, Portugal. ${ }^{3}$ Oporto Faculty of Medicine, Portugal. 
Submit your next manuscript to BioMed Central and take full advantage of:

- Convenient online submission

- Thorough peer review

- No space constraints or color figure charges

- Immediate publication on acceptance

- Inclusion in PubMed, CAS, Scopus and Google Scholar

- Research which is freely available for redistribution 